\title{
Perceptions of Malaria and pattern of treatment seeking behaviour among Tharu and Pahari communities of Jhalari
}

\author{
Budhathoki CB, ${ }^{1}$ BC RK² \\ ${ }^{1}$ Department of Health and Physical Education, Mahendra Ratna Campus, TU, Tahachal, Kathmanndu, Nepal, ${ }^{2} \mathrm{Nepal}$ \\ Health Research Council, Ramshah Path, Kathmanndu, Nepal.
}

\begin{abstract}
Background: Community understanding and practices relating to causation, transmission, prevention and treatment are the main socio-cultural factors that can influence malaria control but studies done social aspect of malaria control are limited in Nepal.

Methods: Cross-sectional study was conducted in 2003 in Jhalari VDC of Kanchanpur district where both Tharus and Pahari communities coexist. Total of 184 households were included in the study through systematic random sampling procedure for household survey. Both qualitative and quantitative methods were applied for data collection.

Results: Fever, headache, chills, shivering, joint pain and spasmodic fever were the most frequently mentioned symptoms of malaria. Though most people knew that mosquito bite might cause malaria fever, they had multiple notions of malaria causations such as hot weather, living near forest, season change, overwork and weakness. They were not clear how a mosquito gets infected and transmit the disease from one person to another. The results showed that people incorporated traditional and modern elements into their concepts of the diseases and treatment strategies. Home remedy with herbs and self-treatment with anti-malarial pills are rare in both communities. Use of government health facility is significantly higher in Paharis than in Tharus. Tharus initially consult their traditional healers and visit the drug retailers in the most cases and government facility in some cases. Tharus were less informed of free diagnosis and treatment of malaria at the government health facilities.

Conclusion: Both Tharus and Paharis are aware of malaria fever and actively seeking medical help from available sources of treatment; however, they are poorly informed of dangerous falciparum malaria and process of the disease transmission through infected mosquitoes. Tharus have less access to the government health facility than Paharis. Thus the improved health services in terms of availability, quality and accessibility, and effective information and communication regarding diseases and services can go a long way in tackling the problem
\end{abstract}

Key words: Malaria, fever, knowledge, perceptions, treatment, health-seeking behaviour.

\section{INTRODUCTION}

Despite decades of great efforts to control it, malaria still remains a serious public health problem in the tropical and sub-tropical regions, where 350-500 million people are infected with malaria and about two millions die each year. ${ }^{1}$ Some three million cases of malaria have been reported in South East Asia Region (WHO) each year. India accounts for about 60 percent of the total cases in the region. Though the reported incidence

Correspondence: Dr. Chitra Bahadur Budhathoki, Department of Health and Physical Education, Mahendra Ratna Campus, Tahachal, Kathmanndu, Nepal. Email: cbbudhathoki@yahoo.com 
rate of malaria in Nepal is lowest $(0.37 / 1000)$ in South Asia, about 70 percent of Nepal's total population live in malaria risk areas. $^{2,3}$ The malaria problem in Nepal is seasonal, focal and unstable. People living in the forest fringe of the Terai and inner Terai and river valleys of the mid hill region are more vulnerable to malaria infection as compared to the people of other areas. ${ }^{4}$ Kanchanpur district is one of the malaria epidemic prone districts as it lies in the Terai region and about 50 percent of its land covered by forest and traversed by perennial rivers and streams. There was a massive malaria epidemic in 2002 in forest fringe areas of the northern part of the district. $^{3}$

Periodic outbreak/epidemics of malaria in different parts of the country signal the collapse of ongoing malaria control public health programs in Nepal. Government reports cite that technical, administrative, financial and logistic problems led to the resurgence of malaria in Nepal in the 1970s and 1980s. The major reasons for the resurgence of malaria may be associated with the socio-economic and political situation rather than the often-cited scientific and technical reasons ${ }^{5}$. Social issues including people's perceptions and their coping strategies were not taken into account while planning and implementing the malaria eradiation/control program. With the failure of technocentric vertical programs and reemergence of infectious diseases, the relevance of social science researches in malaria have been realized. It has widely acknowledged that an understanding of socio-cultural and ecological contexts of malaria transmission is crucial to the success of all efforts to control malaria. ${ }^{6-9}$

\section{METHODS}

This study was conducted in Jhalari village development committee (VDC) of Kanchanpur District that lies in the south-west Terai of the Far-western Development Region of Nepal. It is composed of only seven wards and 17 villages/hamlets. According to population census 2001, the Jhalari VDC comprised of 2717 households and 15526 population comprising 8,086 male and 7,840 female. It is inhabited by the indigenous people, Rana/Dagaura Tharu and the migrated hill people (Brahmin/Chhetris and Dalits). Tharus are indigenous people of the Kanchanpur district. They have their own language, social values and cultural practices distinct from hill origin people.

Out of 17 villages/hamlets, six villages were purposively selected for the study. Three villages: Banjaria, Kasaroul (Tharu settlement) and Mallo Kasaroul (Pahari settlement) are extended behind the Jhalari Market and Sub-Health Post on the northern part of the East-West High Way. Bajnaria is inhabited by both Tharu and hill origin people while Kasaroul is old Ranatharu settlement and Mallo Kasaroul is primarily resided by hill people. Another three villages; namely, Kalapani, Jhandabhoj and Beldandi are about five $\mathrm{km}$ away from Jhalari market and Sub-Health Post in the forest fringe areas of northern part of the VDC. Beldan village is located in the north-east part of the VDC and surrounded by forest. Kalapani is the settlement of the in-migrant hill people (Pahari) while Jhandabhoj is resided by Dangaura Tharu. Beldandi village is composed of both Tharu and Pahari's households.

Household is the sampling unit of the study. List of the households in each villages/settlement was prepared through census method. There were 280 households in three villages (Banjari, Kasaroul and Mallo Kasaroul) located nearby Jhalari market and SHP and 273 households in another three villages such as Kalapnai Santipur, Jhandabhoj and Beldandi situated away from Jhalari Market and SHP. One third of total households from each village were selected by using systematic random sampling procedure for the household survey. First, a household in each settlement was selected randomly and then every third household was included for the interview survey. Household head or an adult member of household who can provide the detail information of the household was interviewed using interview schedule.

Data required for the study were gathered using both qualitative and quantitative methods. Qualitative data were colleted through in-depth interview and focus group discussions. Quantitative types of data were collected through household survey using interview schedule. Thirty-six informants were interviewed using interview guide. Five in-depth interviews and two FGD sessions were conducted in each village/hamlet. Altogether 10 FGD sessions were conducted to explore the community belief, perceptions and beahaviour related to malaria fever. Each in-depth interview as well as FGD were transcribed and expanded immediately after the end of interview and FGD session. Then summary of each interview and FGD was prepared. Two trained persons were recruited to collected required data using interview schedule from the sample households.

In the process of qualitative data analyses, each transcribed in-depth interview and FGD were translated and kept in separate file. Qualitative data were handled and analyzed manually by cut and paste, sorting and multiple charting procedures. Responses and information obtained from the sample survey were quantified assigning codes and number. The carefully coded data were entered in computer using statistical package for social sciences (SPSS) version 13 for windows. Then, 
simple descriptive statistics such as frequency and percentage of variables were computed and cross-tables were produced. Chi-square test was applied to examine the significant difference between dependent and indent variables. Caste/ethnicity and class framework was used to analyze and present data. Qualitative data were integrated with quantitative data.

\section{RESULTS}

\section{Characteristics of respondents}

The study consisted of 133 Pahari and 51 Tharu respondents. Of the total 184 respondents, 136 (73.9\%) were male and 48 females (26.1\%). Only 8 females (15.7\%) from Tharu and 40 females (30.1\%) from the Pahari community participated in the study. Sixty one percent of the respondents were literate. Higher proportion of the respondents from both communities had primary level education. About one-third of the Pahari respondents had educational qualification of SLC and above while only 3 respondents from Tharu community had SLC and above level of education. More than 80 percent respondents in both communities were farmer. Twelve Pahari and two Tharus were employed in teaching and government services (Table 1).
Fever is the most common illness as well as symptom in among the villagers of the study areas as they frequently suffer from different kinds of febrile illnesses. According to the respondents (88\%), malaria fever is the most common illness in the village, followed by typhoid, common cold, fever and pneumonia. People use different local terms to describe febrile illnesses. Rana Tharus uses the terms 'jaro' and Dangaura Tharus 'Juri' for all kinds of fever. Pahari use 'joro' for the same. Ghamjuri in Tharus and kalojoro/tepale in Paharis is a broad term of fever that covers febrile illness such as malaria, typhoid etc occurring in summer and rainy season.

There is a slight variation in the use of terminology for the intermittent fever among Tharus and Paharis. Pahari people still use the term 'tepale' or 'pale' to refer to fever occurring on the every third day while the Tharus use attara/attaria for the same meaning. Tapale and attara/attari are folk malaria believed to be caused by natural as well as supernatural factors, not necessarily by mosquito bites. Most of the Paharis agree that malaria and tepale are similar fevers since both occur on alternate days with rigor. However, Tharus still believe that attara/attaria is a folk illness, which is different from 'maleriya' in terms of causation and treatment. Traditional healers believe that malaria is caused by mosquito bites, but folk malaria tepale/

\begin{tabular}{|c|c|c|c|c|c|c|c|}
\hline \multirow{2}{*}{\multicolumn{2}{|c|}{ Characteristics }} & \multicolumn{2}{|c|}{ Paharis } & \multicolumn{2}{|c|}{ Tharus } & \multicolumn{2}{|c|}{ Total } \\
\hline & & \multirow{2}{*}{$\begin{array}{l}\text { No } \\
93\end{array}$} & \multirow{2}{*}{$\begin{array}{l}\text { Percent } \\
69.9\end{array}$} & \multirow{2}{*}{$\begin{array}{l}\text { No. } \\
43\end{array}$} & \multirow{2}{*}{$\begin{array}{l}\text { Percent } \\
84.3\end{array}$} & \multirow{2}{*}{$\begin{array}{l}\text { No. } \\
136\end{array}$} & \multirow{2}{*}{$\begin{array}{l}\text { Percen } \\
73.9\end{array}$} \\
\hline Sex & Male & & & & & & \\
\hline & Female & 40 & 30.1 & 8 & 15.7 & 48 & 26.1 \\
\hline & Total & 133 & 100.0 & 51 & 184 & 184 & 100 \\
\hline \multirow[t]{3}{*}{ Literacy } & Literate & 82 & 61.7 & 31 & 60.8 & 113 & 61.4 \\
\hline & Illiterate & 51 & 38.3 & 20 & 39.2 & 71 & 38.6 \\
\hline & Total & 133 & 100.0 & 51 & 100.0 & 184 & 100.0 \\
\hline \multirow{5}{*}{ Education } & NFP & 5 & 6.3 & 5 & 16.1 & 10 & 9.0 \\
\hline & Primary & 32 & 40.0 & 16 & 51.6 & 48 & 43.2 \\
\hline & Secondary & 24 & 30.0 & 7 & 22.6 & 31 & 27.9 \\
\hline & SLC and above & 19 & 23.8 & 3 & 9.6 & 22 & 19.8 \\
\hline & Total & 80 & 100.0 & 31 & 100.0 & 111 & 100.0 \\
\hline \multirow{5}{*}{$\begin{array}{l}\text { Main } \\
\text { occupation }\end{array}$} & Farming & 111 & 83.4 & 48 & 94.1 & 159 & 86.4 \\
\hline & Teaching and GO services & 12 & 9.0 & 2 & 3.9 & 14 & 7.6 \\
\hline & Tailoring/Blacksmith & 5 & 3.8 & 0 & 0 & 5 & 2.7 \\
\hline & Other (Retail shop/foreign) & 5 & 3.8 & 1 & 2.0 & 6 & 3.3 \\
\hline & Total & 133 & 100.0 & 51 & 100.0 & 184 & 100.0 \\
\hline
\end{tabular}

Knowledge and perceptions of malaria 
pale/attaria are induced by various factors including hot weather and supernatural forces other than mosquito bites. These traditional concepts of febrile illness are gradually being replaced by biomedical terminologies such as malaria and typhoid. Both Tharus and hill people use the term 'maleriya' derived from medical terms to indicate the fever that is characterized by headache, bodyache, chills and shivering fever on alternative day. They further classify maleriya into two groups: normal maleriya and Pi-efi maleriya or dangerous malaria (probably falcipuram malaria). Normal malaria is clearly characterized by chills, rigor and fever on alternative days and easily treated with anti-malaria tablets. Piefi may or may not be associated with the symptoms of maleriya. Both Tharus and Pahari people believe that $P i$ efi is new febrile illness which is different from normal malaria.

Both Tharu and Paharis are aware of symptoms of malaria. Headache, chill, shivering, intermittent fever and sweating are commonly mention symptoms of malaria. The fever was described by informants as so intense that 'initially you could feel chilling cold and your whole body begins to shiver and then you could feel the heat coming out from your mouth, eyes and ears. Feeling of being very cold was not relieved even if one were wrapped in blankets and quilts; rather s/he likes to bask in sun or sit around the fire to get warm. Chills and high fever usually end with profuse sweating, so excessive that one must put off and squeeze clothes. Backache and pain in joints, finger and lower legs were also described as symptoms of malaria. Symptoms mentioned by informants were clearly distinguished from other febrile illness such as influenza and fever of overwork and tiredness. Chills and shivering fever on alternate day or spasmodic fever are key to recognize malaria fever.

Survey results also reveal that both Thuru and Pahari people in Jhalari VDC are aware of the symptoms of malaria such as fever, headache, chills, rigor, pain in joints and spasmodic fever. There is no significance difference in knowledge of malarial symptoms of Tharus and Paharis. However, the proportion of the respondents reporting chills and rigor is higher in the Paharis than in Tharu people (Table 2). About 20 percent of the Tharu and Hill people reported that nausea and dislike of food as symptoms of malaria. Vomiting and convulsion are common in fetal falciparum malaria. But the respondents failed to report vomiting and convulsion as symptoms of malaria. It indicates that both Tharu and Hill people are not aware of the key symptoms of falciparum malaria. But people living in forest fringe areas where prevalence of malaria is high are more likely to report chills, rigor and vomiting as symptoms of malaria fever than those who live away from the forest fringe.

Table 2. Respondents knowledge about symptoms, causes and transmission of malaria

\begin{tabular}{|c|c|c|c|c|}
\hline \multirow{2}{*}{ Symptoms and perceived causes of Malaria } & \multicolumn{2}{|c|}{ Pahari $\mathrm{N}=133$} & \multicolumn{2}{|c|}{ Tharu $\mathrm{N}=51$} \\
\hline & No & Percent & No. & Percent \\
\hline Fever & 128 & 96.3 & 49 & 96.1 \\
\hline Headache & 122 & 91.7 & 44 & 86.3 \\
\hline Chills and rigor & 105 & 78.9 & 34 & 66.7 \\
\hline Spasmodic fever & 99 & 74.4 & 38 & 74.5 \\
\hline Pain in joint & 80 & 60.2 & 33 & 64.7 \\
\hline Backache & 46 & 34.6 & 17 & 33.3 \\
\hline Nausea and dislike of food & 25 & 18.8 & 9 & 17.7 \\
\hline \multicolumn{5}{|l|}{ Perceived causes } \\
\hline Mosquito bites & 125 & 93.9 & 49 & 96.1 \\
\hline Hot weather & 92 & 69.2 & 22 & 43.1 \\
\hline Living near forest & 79 & 59.4 & 10 & 19.6 \\
\hline Hard work and weakness in hot season & 33 & 24.8 & 9 & 17.6 \\
\hline Wet in rain, dew and season change & 43 & 32.33 & 15 & 29.41 \\
\hline Dirty environment & 70 & 52.6 & 23 & 45.1 \\
\hline Not spraying insecticide & 96 & 72.2 & 28 & 54.9 \\
\hline \multicolumn{5}{|l|}{ Malaria transmission } \\
\hline Infected mosquito coming from patient & 42 & 31.6 & 16 & 31.5 \\
\hline Mosquito coming from filth and dirty water & 38 & 28.6 & 3 & 5.9 \\
\hline Mosquito that has bitten pigs and ducks & 7 & 5.3 & 13 & 25.5 \\
\hline Poisonous mosquito from jungle & 15 & 11.3 & 7 & 13.7 \\
\hline No idea & 31 & 23.3 & 12 & 23.5 \\
\hline
\end{tabular}


In Tharu and Pahari communities, there are multiple notions of malaria causation among the local residents, although they knew that mosquito bites may cause febrile illness and malaria. Ninety-six percent of the respondents in both communities associated the cause of malaria to the bite of mosquito. They also included other causes such as hot weather, living near forest, hard work and weakness, dirty environment, and getting wet and season change. Proportions of the respondents reporting other causes are higher in the Pahari communities than in Tharus. Seventy two percent of the Pahari respondents reported that malaria re-emerged as the government stopped the insecticide spraying.

Regarding malaria transmission, only 33.1 percent of the study subjects from both communities knew that malaria could be transmitted from one person to anther person through the bite of infect mosquito (Table 2). Twenty three percent of the respondents had no any idea how malaria is spread in a communities. About 30 percent of the Pahari respondents believed that mosquito coming from dirty places may transmit malaria in human population, while one fifth of the Tharu respondents believed that mosquito can bring malaria from pigs and ducks to human beings. More than 10 percent of the respondents from both communities believed that poisonous mosquito coming from jungle can spread malaria in communities.

Both Tharu and Pahari communities believe that malaria primarily occurs in hot season (from April to September) and regard it as illness due to garmi (hot weather). Some Pahari informants living in forest fringe believe that poisonous or hot and humid air flowing from forest cause and spread malaria among people living nearby forest. Many Pahari people stated that working in the farmland for several hours in summer/monsoon seasons weakened the body and the chance of getting malaria becomes high in summer and monsoon season. Tharus and Pahari people participating in FGD sessions agreed that all types of mosquito bites could not spread malaria; only poisonous or infected mosquitoes can cause or spread malaria in the community. The villagers often opine that small size and brown colored mosquitoes that are abundant around houses in summer and monsoon may not cause illness. Big and black or spotted or strange colored mosquitoes are poisonous because they usually come from Jungle and dirty places. Pahari informants believe that mosquitoes carried blood and toxin from other persons and animals and injected into their blood while feeding on human blood. When blood of an animal or a person is mixed in another's blood, it causes illness. Only a few educated respondents correctly reported that malaria is caused by plasmodium parasites and transmitted by infected female anophlese mosquitoes.

\section{Pattern of treatment seeking behaviour}

Anti-malarial drugs are provided free of cost at SubHealth Posts and Health Posts in rural malaria endemic areas, but diagnostic facilities are not available in most of the peripheral health facilities. Almost all respondents from both communities knew that malaria could be best treated with anti-malaria tablets, but only five educated Pahari and two Tharu respondents stated the name of drugs such as Chloroquine and Primaquine. In Jhalari VDC, government facility, SHP is the major source of the malaria treatment. However, all people do not seek treatment from government facilities because they also seek medical help from other sources such as home remedy, self-treatment, private practitioners/drug retailers and private clinics. Home remedy (use of locally available herbs, roots, barks and leaves by individual or family) is very low in both communities (Table 3) because most of the respondents were not aware of the home remedy that could cure malaria fever. Some Pahari informants said that they used to treat febrile illness with herbs found in hill and mountain forest before coming to settle in the Terai, but they were not familiar with herbs in the Terai region. A few informants from both communities attempted to treat malaria fever with home remedy prepared with neem's leaves (Azadirachta indica) neem's leaves.

Table 3. Patterns of treatment seeking behvaiour by Pahari and Tharu communities, and location of villages from SHP facility

\begin{tabular}{|c|c|c|c|c|c|c|c|c|c|c|c|}
\hline \multirow{2}{*}{\multicolumn{2}{|c|}{ Pattern of treatment }} & \multicolumn{2}{|c|}{ Hill $N=133$} & \multicolumn{2}{|c|}{ Tharu $\mathrm{N}=51$} & \multicolumn{2}{|c|}{ Nearby SHP } & \multicolumn{2}{|c|}{ Away from SHP } & \multicolumn{2}{|c|}{ Total } \\
\hline & & No & $\%$ & $\mathrm{~N}$ & $\%$ & No. & $\%$ & No & $\%$ & $\mathrm{~N}$ & $\%$ \\
\hline 1 & Home remedy & 12 & 9.8 & 3 & 6.4 & 6 & 11.5 & 9 & 7.7 & 15 & 8.9 \\
\hline 2 & Self-treatment & 21 & 17.2 & 4 & 8.5 & 10 & 19.2 & 15 & 12.8 & 25 & 14.8 \\
\hline 3 & Traditional healers & 15 & 12.3 & 28 & 59.57 & 18 & 34.6 & 25 & 21.4 & 43 & 25.4 \\
\hline 4 & SHP & 87 & 71.3 & 22 & 46.8 & 26 & 50.0 & 83 & 70.9 & 109 & 64.5 \\
\hline 5 & Private practitioner & 41 & 33.6 & 28 & 59.57 & 27 & 51.9 & 42 & 40.8 & 69 & 40.8 \\
\hline 6 & Hospital & 7 & 5.7 & 2 & 4.2 & 4 & 7.7 & 5 & 4.3 & 9 & 5.3 \\
\hline
\end{tabular}


Self-treatment refers to any treatment that does not involve consulting a health care provider or traditional healer. ${ }^{10}$ Like home remedy, practice of self-treatment for malaria is not popular in both communities. However, the practice of self-treatment for malaria cases is higher in the Pahari communities (17.2\%) than in Tharus (8.5\%). While discussing with the Pahari people, the participants argued that it was unwise to attempt self-medication in malaria fever because it could make it difficult for detecting malaria through blood tests. Therefore, they like to avoid antipyretics and use anti-malaria drugs which are not easily available in the market.

Traditional healers are immediate source for treatment of any illness in villages. Use of traditional healers is significantly higher in Tharus than in Pahari communities. The Tharus of the Terai usually consult bharra / guruwas (traditional healers) first when they fall ill. Bhagiram Thar of Jhandabhoj said; “As per our traditional and cultural practices, we consult our guruwa first in almost all types of illness including malaria fever to confirm whether bhutta (evil spirits) are implicated in the illness". Tharus still believe that traditional healers can successfully cure many illnesses, including fever. Paharis also seek help from traditional healers when they ascribe illness to evil spirit and intermittent fever to tapale illness. Many Pahari respondents said that they did not consult Dhamis or Vaidyas in malaria fever as it was not caused by evil spirit. Traditional healers also refer their patients to medical facilities if they do not see any role of evil spirits and patients present the symptoms of malaria fever.

The use of government health facility, SHP is significantly higher in the Pahari (71.3\%) than in the Tharu community (46.8\%). Pahari people usually visit the SHP facility when they present symptoms of malaria such as chills, rigor and intermittent fever because they are aware of the health service and diagnostic facilities of Jhalri SHP. Surprisingly, use of the SHP facility is higher among the people who live in forest fringe and away from the Jhalari SHP than in those who live nearby SHP and Jhalari Market. Those live in forest fringe areas frequently suffer from malaria and attend the SHP for blood test and proper treatment of malaria. But many Tharu were not aware of even free treatment of malaria fever at SHP and microscopic diagnostic facility. Tharus usually bypass government health facility and consult drug retailers since they perceive the SHP as poor health facility. Tharus are more likely to consult private practitioners/drug retailers than do the Pahari people. The use of the drug retailers is highest in economically better off households of both communities. But Pahari people from poor and not-so-poor strata visit the SHP facility more frequently as compared to proportion of the better off who seek treatment from the SHP in malaria fever. Likewise, higher proportions of the Tharus visiting the SHP were from the very poor and poor family background. Hospitals services are rare and unusual options for the villagers. Only one Tharu and eight Pahari visited the hospital for treatment malaria after several days of symptoms recognition when local healers and practitioners failed to cure illness.

Table 4. Socioeconomic status and treatment seeking behaviour

\begin{tabular}{|c|c|c|c|c|c|c|}
\hline \multirow[t]{2}{*}{ Sources of treatment } & \multicolumn{3}{|c|}{ Hill people } & \multicolumn{3}{|c|}{ Tharu } \\
\hline & Poor & Not-So-Poor & Better off & Poor & Not-So Poor & Better off \\
\hline Traditional healers & $11(20.37)$ & $4(8.0)$ & 0 & $13(72.2)$ & $1354.8)$ & $2(40.0)$ \\
\hline SHP & $43(79.6)$ & $35(70.0)$ & $9(50.0)$ & $10(55.6)$ & $11(45.8)$ & $1(20.0)$ \\
\hline Private practitioner & $13(24.1)$ & $19(38.0)$ & $9(50.0)$ & $10(55.6)$ & $14(58.8)$ & $4(80.0)$ \\
\hline Hospital & 1 (1.9) & $3(6.0)$ & $4(22.2)$ & 0 & $1(4.2)$ & $1(20.0)$ \\
\hline
\end{tabular}

Table 5. Delay treatment seeking behaviour in the Tharu and Pahari communities

\begin{tabular}{|c|c|c|c|c|c|c|}
\hline \multirow{2}{*}{ Delay in days } & \multicolumn{2}{|c|}{ SHP attended by } & \multirow{2}{*}{ Total } & \multicolumn{2}{|c|}{ Private practitioner } & \multirow{2}{*}{ Total } \\
\hline & Pahari & Tharu & & Pahari & Tharu & \\
\hline One day & $24(25.8)$ & $2(7.7)$ & $26(21.8)$ & 8 (19.5) & $4(16.7)$ & 12 (18.5) \\
\hline Two to three & $44(47.3)$ & $15(57.7)$ & $59(49.6)$ & $18(43.9)$ & $10(41.7)$ & $28(43.1)$ \\
\hline Four or more & $25(26.9)$ & $9(34.6)$ & 34 (28.6) & $15(36.6)$ & $10(41.7)$ & $25(38.5)$ \\
\hline Total & $93(100)$ & $26(100)$ & $119(100)$ & 41 (100) & 24 (100) & 65 (100) \\
\hline
\end{tabular}


Most people do not seek any treatment modality as soon as they suffer from headache, chills and fever. During febrile illness, many people wait home to see whether illness requires no treatment. Only eight percent of the Tharus and 26 percent of the Pahari who had malaria fever visited the SHP facility after delaying one day. Majority of the Tharus and $\mathbf{4 7 . 3}$ percent of the Pahari people sought treatment after two-three days of illness. The proportion of the people seeking treatment from the SHP and Drug Retailers after four days is higher in Tharus than in the Pahari communities. It is possible because the majority of the Tharus consult their traditional healers before visiting health facilities. While examining the treatment sequence, 48.4 percent of Pahari people initially visited the SHP and 59.3 percent selected the SHP as second choice of treatment while majority of the Tharus consulted traditional healer in the first position. The Tharus selected the Drug Retailers in 50 percent cases and SHP in 32.4 percent cases of malaria fever. The use of traditional healers in Tharu communities gradually decrease while switching from first to third position of treatment while the use of Drug Retailers continue to increase until the third position. Again the use of the traditional healers increases in the fourth position in both communities. It indicates that if biomedical treatments failed to cure illness, they again turned to the service of the traditional healers. synonym for malaria fever. Local people like to use the biomedical term Maleriya (malaria) to refer to illness associated with headache, chills/rigor, joint pain and intermittent fever. This might be due to the influence of health care providers who usually use medical terms to label illness.

The results showed that knowledge about the symptoms of normal malaria (Plasmodium vivax) was very high in both communities. Almost all respondents from both communities had knowledge of at least one of the classical symptoms such as chills, rigor, shivering fever or intermittent fever. Despite high awareness of symptoms of normal malaria, many villagers have no clear idea of dangerous malaria (falciparum malaria) that is locally called Pi-efi malaria. Only some Paharis who had recent experience of such Maleriya described symptoms of it, but they were not aware of severe manifestations of dangerous malaria such as vomiting, fainting and convulsion of falciparum malaria. Such severe manifestations that require immediate medical attention are locally interpreted as 'folk illness' in terms of evil spirits like bhutta in Tharu communities and jharnu bimar in Pahari communities. Present malaria control activities have ignored the issue of dangerous malaria that is emerging in different part of the countries.

\begin{tabular}{|c|c|c|c|c|c|c|c|c|}
\hline \multirow{2}{*}{ Treatment sequence } & \multicolumn{4}{|c|}{ Pahari } & \multicolumn{4}{|c|}{ Tharu } \\
\hline & $\mathrm{T} 1$ & T2 & T3 & T4 & $\mathrm{T} 1$ & T2 & T3 & T4 \\
\hline Self-treatment & 22.1 & 5.1 & 0 & 0 & 15.2 & 0 & 0 & 0 \\
\hline Traditional healers & 5.7 & 5.1 & 11.1 & 50 & 52.2 & 14.7 & 16.7 & 33.3 \\
\hline SHP & 48.4 & 59.32 & 27.8 & 0 & 17.4 & 32.4 & 16.7 & 0 \\
\hline Private practitioner & 22.1 & 23.7 & 38.9 & 12.5 & 15.2 & 50 & 41.7 & 33.3 \\
\hline Hospital & 1.6 & 5.1 & 11.1 & 12.5 & 0 & 0 & 8.3 & 33.3 \\
\hline Others & 0 & 1.7 & 11.1 & 12.5 & 0 & 2.9 & 16.7 & 0 \\
\hline
\end{tabular}

Note: T1 = Treatment First, T2 = Treatment Second, T3 = Treatment Third, T4 = Treatment Fourth

\section{DISCUSSION}

People's perceptions regarding malaria fever in Tharu and Pahari people are deeply embedded in their social, cultural belief systems and health care practices that exist in the community. Cultural specific terminologies such as 'tepale' or 'pale' fever are used in the Pahari and 'Attaria / Attara' in the Tharu community to indicate a particular category of fever that occurs with shivering on alternate day. Both Pahari and Tharus believed that the key symptoms of Tepale or pale, Attaria / Attara and malaria are the same, but these terms are rarely used as
With respect to the causes of malaria, almost all respondents from both communities implicated mosquito bite as a possible cause of malaria; however, they do not adhere only to the biomedical notion of disease causation. They include other causes such as hot weather or season, overwork, weakness, dirty environment and living in forest or forest fringe. Pahari people are more likely to include hot weather and living nearby forest as possible causes of malaria in other causes than do the Tharus who have living in hot weather and forest fringes of the Terai for centuries. Other studies also reported that malaria was perceived to be caused due to drinking contaminated water and bathing with dirty 
water, changing environment and weather ${ }^{14}$ and evil spirits and witchcrafts. ${ }^{11-13,15-17}$ However, malaria is not attributed to drinking contaminated water or evil spirits in both communities. Many villagers cannot distinguish between the cause and transmission. For the villagers, the hot air and dirty surroundings, and mosquito bites are both the causes as well as sources of the transmission of malaria. Most villagers have no idea how mosquitoes acquire parasites and transmit them from one person to another. Health care providers do not explain the role of infected mosquitoes and parasites in malaria infection to the poor and illiterate patients and those who are from Tharus communities presuming that they do not understand biomedical facts. There has been very little IEC activities about malaria supposition that people have already been aware of it through the intensive malaria eradication/control program in the past.

Home treatment and self-medication with anti-malarial tablets is not common in the villages because most villagers have no idea of home remedy and other medicines for malaria. In some cases, self-treatment begins with the use of antipyretic Paracetamol tablets in Pahari communities. Though almost all Tharus follow traditional healing ritual, exclusive use traditional ritual healing is very rare. They may use only one or both of biomedical and traditional sources sequentially or concurrently in a course of illness because they easily combine modern medicine with traditional practices in Nepal. ${ }^{18}$ Sixty-nine percent of the households in which illness occurred, sought treatment from different sources and of those, 55 percent first visited traditional healer and then visited the health care facilities. ${ }^{19}$ There is no significant difference in the patterns of health-seeking behaviour of people who live nearby and away from the SHP facility. However, people living away from health facility often visit the Jhalari SHP after several days of the onset of symptoms.

Both Tharus and Pahari people prefer modern treatment in several illnesses including malaria and typhoid fever that belong to the rog / bimar category having naturalistic origin. Anti-malaria tablets are well accepted among them. However, the government health facility is not equally used by the Tharus and Paharis. The use of SHP facility is significantly higher in the Pahari communities because they are aware of that malaria is diagnosed and treated free of cost at government health facility. But most Tharus are not aware of free diagnosis and treatment of malaria at SHP. Therefore, they often consult local private practitioners/drug retailers in second position after consulting traditional healers. Furthermore, they have no social relation with modern health care providers and lack the capacity to interact with the SHP staffs belonging to the Pahari Brahmin / Chhetris who often bias against the Tharus. Due to the glaring status gap and language barrier between the staff and them, the Tharus' problems may not be properly dealt at the public facility. Therefore, they have a tendency to avoid the government facility. Communication barrier between the Oraon tribes of India and health personnel acts as an important obstacle to access to the Health Centre. ${ }^{20}$

Cultural practices of seeking help from traditional healers in Tharu communities may lead to delay in visiting health care facilities. Higher proportion of the Tharus suffering from malaria fever is likely to delay some days in attending health facility as compared to those of the Pahari people. One of the main reasons for delaying in seeking modern health care is to depend on their indigenous health care in Nepal before coming to the hospital. ${ }^{21}$ A considerable proportion of the Paharis promptly visit the SHP facility in malaria cases without doing anything at home because they rarely use home treatment, anti-pyretic tablets and traditional healers in probable cases of malaria. But the poor people delay several days in seeking medical help due to the lack of money and easy access to health facility. "Waiting and seeing" before seeking modern treatment in febrile illness was mentioned by the villagers in Nepal is common in developing countries either due to financial constraints or as a tactic in the decision-making process. ${ }^{22,23}$

The findings of this study reveal that people are aware of malaria and actively seeking medical help from the available sources of treatment. But the present malaria control activity and public health facilities are grossly inadequate to meet the felt need of the community. Lack of drugs and microscopic examination facility for malaria in the government health care facilities are major concern for most patients. Moreover, poverty and process of marginalization of the Tharus are major barriers to access the government health facility.

\section{CONCLUSION}

The health-seeking behaviour of peoples is, by and large, influenced by their socio-economic condition, cultural practices, caste / ethnic background and perceive quality of the health facility. Government health policy and malaria control program should consider these issues in order to change health-seeking behaviour of people and successfully implement the disease control activities in rural areas. Thus the improved health services in terms of availability, quality and accessibility, and effective health communication regarding diseases and services can go a long way in tackling the problem.

\section{ACKNOWLEDGEMENTS}

The study was supported by UNDP/World Bank/WHO Special Program for Research and Training in Tropical Diseases (TDR). I am grateful to Professor Imrana Qadeer 
and K. R. Nayar, Centre of Social Medicine and Community Health of Jawaharlal Nehru Univeristy, New Delhi for her valuable guidance. We are indebted to all participants in the focus group discussion and in-depth interview, and other community members for their participation in the study.

\section{REFERENCES}

1. WHO/RMB/UNICEF. World Malaria Report 2005. Geneva: World Health Organization.

2. Ministry of Health, Epidemiology and Disease Control Division. The annual internal assessment of malaria and Kala-azar control activities 2002. Kathmandu: Ministry of Health; 2004.

3. Ministry of Health, EDCD. Proposed Five Year Strategic Plan (2001-2005). Roll Back Malaria. Kathmandu: Ministry of Health; 2001.

4. Banerjee MK, Palikhe N, Shrestha BL and Vaidya RG. Persistent malaria transmission in forests of central Nepal. In: Forest Malaria in Southeast Asia. Delhi: Malaria Research Centre/ICMR; 1991. p. 155-69.

5. Farid MA. The malaria program from euphoria to anarchy. World Health Forum 1980;1(1):28-33.

6. Oaks SC, Mitchell VS, Pearson GW, Carpenters CP. Social and behavioural aspects of malaria. In: Oaks SC et al Editors. Malaria: Obstacles and Opportunities. Washington DC: National Academy Press; 1991. p. 257-71.

7. Tanner M, Vlassoff C. Treatment seeking behaviour for malaria: A typology based on endemicity and gender. Social Science and Medicine 1998;46(4-5):523-32.@

8. Agyepong IA. Malaria: ethno-medical perceptions and practice in Adangbe farming community and implications for control. Social Science and Medicine 1992;35(2):131-7.

9. Helitzer-Allen DL, Machero A, Wirima J, Kendall C. Testing strategies to increase use of Chloroquine chemoprophylaxis during pregnancy in Malawi. Acta Tropica 1994;58:255-66.

10. McCombie SC. Self-treatment for malaria: the evidence and methodological issues. Health Policy and Planning 2002; 17(4):33344.

11. Singh N, Singh MP, Saxena A, Sharma VP, Kalra NL. Knowledge, attitude, beliefs and practice (KABP) Study related to malaria and intervention strategies in ethnic tribals of Mandla, Madhya Pradesh. Current Science 1998;75(12):1386-90.

12. Espino F, Manderson L, Acuin C, Domingo F, Ventura E. Perceptions of Malaria in a low endemic area in the philippines: transmission and prevention of disease. Acta Tropica 1997;63:22139.

13. Kengeya-Kayondo JF, Seeley JA, Kajura-Banjenja E, Kabunga E, Mubiru E, Sembajja F, et al. Recognition, treatment seeking behaviour and perception of cause of malaria among rural women in Uganda. Acta Tropica 1994;58:267-73.

14. Yadav SP, Tyagi BK, Ramnath T. Knowledge, attitude and practice towards malaria in rural communities of the epidemic-prone Thar desert, North Western India. Journal of Communicable Diseases 1999;31(2):127-36.

15. Govere J, Durrheim D, la Grange K, Mabuza A, Booman M. Community knowledge and perceptions about malaria and practices influencing malaria control in Mpumalanga province, South Africa. South African Medical Journal 2000;90(6):611-5.

16. Hausmann-Muela S, Ribera JM, Mushi AD, Tanner M. Medical syncretism with reference to Malaria in a Tanzanian community. Social Sciences and Medicine 2002;55:403-13.

17. Nuwaha F. People's perception of malaria in Mbarara, Uganda. Tropical Medicine and International Health 2002;7(5):462-70.

18. Stone L. Illness, Hierarchy and Food. Symbolism in Hindu Nepal. Ph.D Thesis, Brown University, USA, 1977.

19. Jimba M, Poudel AK, Wakai S. The need for linking health careseeking behaviour and health policy in rural Nepal. South-east Asian Journal of Tropical Medicine and Public Health 2003;34:462-3.

20. Sahu SK. Health Culture in Transition: A Case Study of Oraon Trive in Rural and Industrial Nexus. 1st ed. Delhi: Khama Publishers; 1991.

21. Subedi J. Modern health services and health care behaviour: a survey in Kathmandu, Nepal. Journal of Health and Social Behaviour 1989;30:412-20.

22. Asenso-Okyer WK, Dzator JA. Household cost of seeking malaria care. a retrospective study of two districts in Ghana. Social Science and Medicine 1997;45(5):659-67.

23. Ryan GW. What do sequential behavioural patterns suggest about the medical decision-making process: Illness in a rural Cameroonian village. Social Science and Medicine 1998;46(2):209-25. 